DOI: 10.1515/ausp-2015-0051

\title{
Potential Ambiguity Translation Performances within Legal Language Institutional Nomenclature
}

Ambiguous Valences of Performance in Contract Language

\author{
Diana OŢĂT \\ University of Craiova \\ Department of British, American and German Studies, Craiova \\ dianaotat@yahoo.com
}

\begin{abstract}
Motivated by a paradoxical corollary of ambiguities in legal documents and especially in contract texts, the current paper underpins a dichotomy approach to unintended ambiguities aiming to establish a referential framework for the occurrence rate of translation ambiguities within the legal language nomenclature. The research focus is on a twofold situation since ambiguities may, on the one hand, arise during the translation process, generated by the translator's lack of competence, i.e. inadequate use of English regarding the special nature of legal language, or, on the other hand, they may be simply transferred from the source language into the target language without even noticing the potential ambiguous situation, i.e. culture-bound ambiguities. Hence, the paper proposes a contrastive analysis in order to localize the occurrence of lexical, structural, and socio-cultural ambiguities triggered by the use of the term performance and its Romanian equivalents in a number of sales contracts.
\end{abstract}

Keywords: unintended ambiguities, legal translation

\section{Introduction}

The paper addresses some specific problems in the attempt to localize the nature of ambiguities as an unintended outcome of legal translation. Without claiming comprehensiveness, our scientific motivation regards the paradoxical emergence of ambiguities in legal documents and, more specifically, in contracts, for in such texts we have to distinguish first and foremost between intended and unintended ambiguities. Such a distinction is mainly necessary forasmuch as various scholars claim that legal language and contract language are both extremely precise and vague (Vîlceanu 2004). In this respect, Crystal and Davy (Crystal and 
Davy 1979: 210) state that "exactness of meaning is a tricky thing to calculate". Similarly, Cao (Cao 2007: 23) endorses that "the English legal language is full of imprecise and ambiguous expressions which are not necessarily intended". This approach to unintended ambiguities also represents the focal aim of the present research paper as we shall dwell on the identification of unintended ambiguities in contract texts. In the following sections, we shall propose an analysis of unintended ambiguities employed at the linguistic and cultural level alike.

\section{Ambiguities - definitions and meaning}

Conventional definitions of the term and the concept of ambiguity are provided by various standard dictionaries, which conceptualize ambiguity as something difficult to understand. In this climate of opinion, Longman Dictionary of Applied Linguistics and Teaching defines the noun ambiguity and its derivative adjective ambiguous as "a word, phrase, or sentence which has more than one meaning" (Richards and Schmidt 2002: 24). From a similar perspective, A Dictionary of Law terms ambiguity as "uncertainty in meaning" (Martin 2003: 24). This definition matches our previously established distinction between intended and unintended ambiguities, hence, legal ambiguity targets two technical deliverables, namely a patent ambiguity - obvious to anyone looking at the document, for example, when a blank space is left for a name, and a latent ambiguity, which at first appears to be an unambiguous statement, but the ambiguity becomes apparent in the light of knowledge gained other than from the document.

Following the same pattern, the term ambiguous, functioning as an adjective, is said to refer to a notion which reveals more than one meaning, so that it is not clear which is instead (Summers et al. 2005: 39).

However, although our approach to ambiguities is derived from mainstream literature, we shall further use the phrase unintended ambiguities instead of latent or patent ambiguities, on the grounds that our investigation aims at identifying and describing ambiguity dimensions rather than legal ambiguous interpretations (Vîlceanu 2008).

\section{Localization of translation ambiguities within legal language institutional nomenclature}

Two prevailing translation-oriented co-ordinates converge toward a referential framework for the occurrence of unintended ambiguities, which, albeit their multifaceted perspectives, may be regarded as two overlapping dimensions. 


\subsection{Linguistic approach to translation ambiguities}

A plethora of linguistic perspectives postulated by leading scholars led to various interrelated taxonomies, as linguistic unintended ambiguities have been systematically described in terms of lexical, grammatical, semantic, or pragmatic features.

Under the circumstances, Lyons postulates that ambiguity may occur when using partial homonyms, as at this level ambiguity "depends upon a difference in the lexical meaning of two partial homonyms," though absolute homonyms may also produce ambiguity (Lyons 1995: 55). Admittedly, the author reinforces that lexical ambiguity is in close relation to grammatical ambiguity, and analysing homonyms or polysemes in terms of grammatical equivalence or non-equivalence we could avoid ambiguity. Strictly referring to ambiguities as expression forms, Cruse makes the distinction between the lexical and grammatical ambiguity of a structure (Cruse 2006: 17) and, similarly, Bussmann differentiates between lexical, semantic, and syntactic ambiguities (Busmmann 2006: 50). Nonetheless, in order to avoid ambiguities, Bussmann highlights the importance of syntactic relations, which the author labels "polysyntacticity" and "constructional homonymy," while lexical ambiguities are discussed in terms of semantic polysemy or homonymy.

In respect to the occurrence of lexical and grammatical ambiguities, various taxonomies have been corroborated, starting from Ullmann (Ulmann 1977 qtd by Tambunan 2009), who proposes a classification model comprising three types of ambiguities: phonetic, grammatical, and lexical ones. Leech endorses lexical and structural ambiguities, and validates lexical ambiguities as closely related to the semantic meanings of words, while structural ambiguities derive from grammatical and syntactical forms (Leech 1980: 7-16).

Consequently, our endeavour to spot legal ambiguities linguistically will imply two distinct interpretations revealed either by word forms and phrases particularities or by more complex structures, which, according to Yule, "are represented differently in deep structure" (Yule 2006: 88).

Defined by Trosborg as an instance of Language for Special Purposes (LSP), which further frames a series of highly specialized sub-languages, legal language is regarded by Tiersma as an "archaic, formal, impersonal, and wordy or redundant" language, which can be relatively precise or quite general or vague, depending on the strategic objectives of the drafter" (Trosborg 1997: 17). While a lawyer or a legal practitioner is mainly concerned with the understanding of law, a linguist and, similarly, a translator are concerned with how to give meaning of law in communication (Tiersma 2008: 7).

Undeniably, linguistic unintended ambiguities do occur in legal language and subsequently in contract language if we put trust in Cao, who postulates 
the existence of "lexical and structural or syntactic ambiguities" within legal documents. Hence, unintended linguistic ambiguities may occur due to lexical variations between the source and target language, the author suggesting that "a basic linguistic difficulty in legal translation is the absence of legal equivalent terminology across different languages" and certain terms may generate faulty comprehension, being further ambiguously reproduced in the target language.

The typical nature of legal language should be taken into consideration as an instance of LSP, a highly specialized language; Cao argues that it is the specific, highly specialized style of each legal system that would further involve unintended ambiguities, the author claiming that this aspect is more evident in contracts between foreign business partners (Cao, 2007).

Convincingly, Tiersma advocates that legal language displays a "tremendous amount of technical terms" (Tiersma 2008: 15), which, going back to Crystal and Davy's seminal statement, are "those words which appear to have a very precise reference" (Crystal and Davy 1979: 210). However, ambiguity may occur in using or translating potential deliberate vague words such as rule, regulation, norms, terms, etc.

What may appear more ambiguous than the use of archaisms or technical terms are common words used with uncommon meaning. The occurrence of ambiguities by using such words within legal documents is advanced by Tiersma, who states that "there are many words that have both an ordinary as well as a legal meaning," defined as "legal homonyms" (Tiersma 2008: 16). Likewise, enlarging upon common words with specialized meanings, we mention Cao's point of view, which indicates that apart from the unequivocal legal words, there are many other words in legal documents that have both an ordinary meaning and a technical one, rendered by the author as "ordinary versus legal meanings" (Cao 2007: 53).

Translation ambiguities may be encountered at the structural level as well. Either at the phrase or sentence level, ambiguities may occur by applying calques: effective costs - costuri effective; functional equivalents occupational health and safety securitate şi sănătate în muncă, natural or legal person - persoană fizică sau juridică or shifts to avoid any misunderstandings - pentru evitarea oricăror neînțelegeri.

Considering all these markers that define the field of contract language, we can further assume that such an environment becomes even more productive for the occurrence of ambiguous situations (Oțăt 2011: 204-209).

\subsection{Socio-cultural approach to translation ambiguities}

It is held that language is an expression of culture and distinctiveness of its speakers, highly influencing the way its members perceive the world. Subsequently, sociolinguistic ambiguities emerge whenever cross-cultural language barriers distort meaning in translation. 
From the perspective of the translation process, such ambiguities are fairly recurrent, especially when dealing with culture-bound items. That is why, in order to localize and, moreover, to avoid ambiguities when translating legal documents, we should try to compare the cultures of two societies, as Nord considers that translation is a phenomenon pertaining to each culture (Nord 1993: 34). Correspondingly, the avoidance of ambiguities may succeed based on an increased awareness of the socio-cultural context, which Hatim and Mason regard as a more important variable than text genre (Hatim and Mason 1990). In order to avoid ambiguities, we should regard text interpretation within the larger social context, adopting a translation-oriented strategy which would also assist us locate and avoid ambiguities, especially when translating culture-bound items. Next, we strengthen our approach to ambiguities by the perspective postulated by Nida, who highlights the importance of biculturalism in successful translation as even more important than bilingualism since words only have meanings in terms of the cultures in which they function (Nida 2001: 82).

However, we should not overlook the existence of cultural gaps between the source language and the target language, the utmost notorious dispute in approaching all of the culture-specific concepts which occur in the source language but are totally unknown in the target language. Under the circumstances, ambiguity recognition and avoidance becomes a hard nut to crack.

Based on the wide range of strategies and procedures envisaged for translation, we keep considering the translating activity within a social context. Aiming at localizing socio-cultural bound ambiguities as a product of legal translation, it is worth considering a twofold approach postulated by various researchers. On the one hand, ambiguities may simply occur on account of the special nature of legal language, as it implies highly technical linguistic constrains, compelling the translator to a lifelong learning and professional development. On the other hand, we should be aware of the various differences between legal systems. Thus, besides its highly technical facet, we should be aware that legal language is not universal for all speech/cultural communities, but, as Cao pointed out, "it is tied to a national legal system"; it is a social practice, and thus legal texts necessarily bear the imprint of such practice or organizational background (Cao 2007: 28).

Still, it is not only the peculiar characteristics of each legal system which may lead to ambiguities, but the cultural differences as well. We could say that it is due to cultural differences that specific legal systems have been developed among different societies, concurring with Cao in that as "language and culture or social contexts are closely integrated and interdependent". Subsequently, in order to localize and avoid ambiguity, translators have to make hard decisions, sometimes within the constraints of language, which highly affects and influences the performance of a translator (Oțăt 2011: 204-209). 


\section{Ambiguous valences of performance: a corpus-based analysis}

In what follows, we shall propose a corpus-based analysis in an attempt to establish at what levels unintended ambiguities occur during the translation process, i.e. during the translation of English contracts into Romanian.

Based on the previously illustrated dichotomous approaches to the occurrence of ambiguities either due to ambiguous instances caused by translators themselves during the translation process - mainly linguistic ambiguities - or the transfer of those ambiguous instances from the source language without any further attempt at clarification, i.e. cultural-bound ambiguities, we further intend to carry out a contrastive analysis in order to localize the occurrence of lexical, structural, and socio-cultural ambiguities caused by the use of the term performance and its Romanian equivalents in a number of sales contracts, namely 6 EnglishRomanian bilingual contracts.

Acknowledging that most of the analysed contracts contain confidentiality clauses, we shall avoid disclosing such classified information as contract data, addresses, prices, or sums. Additionally, due to scope and limitations, we shall refer to the analysed texts by using numerical organization according to their proper-name abbreviations accompanied by their drafting or registration date. At the end of the paper, a numerically organized list will be attached, revealing both the abbreviated forms and their corresponding complete titles.

\subsection{Lexical and structural approach}

In terms of legal language lexical approach, the term performance - efectuare, funcționare, performanță is rendered as common word with a technical meaning, referring specifically to the accomplishment of conditions required by a contract.

Regarding the use of this term, it is worth taking into consideration that in Romanian the noun performance does not have a single, precise equivalent, as various definitions have been assigned to this term. In LSP contexts, namely in the Dicționar economic englez-român, performance is defined as I. îndeplinire, efectuare, săvârşire; faptă II. funcționare III. performanță (Năstăsescu 2009: 265). Such examples have also been encountered within our analysis, where noun phrases like the complete and secure performance - finalizarea integrală şi în sigurantă have been properly used and translated in the analysed texts.

However, in example (1), we can speak of an ambiguous meaning of the English noun phrase complete and secure performance and the Romanian equivalent finalizarea integrală şi în sigurantă, as the term performance - finalizarea integrală might have in this excerpt a second interpretation, i.e. "the act of doing a piece of work" (Summers et al. 2005: 1050), which would mean efectuare. Even 
though the counterpart of the term performance, namely finalizare, is lexically precise, ambiguity might arise from the original variant of the text, where performance might have been used with its general standard meaning, i.e. the act of doing a piece of work, duty, and not necessarily referring specifically to the accomplishment of conditions required by a contract.

(1) $2.1[\ldots]$ all the works which are necessary to fulfil the conformity with the contract documents, the ones that arise from the contract duties as well as the ones that are not mentioned but which are necessary for the complete and secure performance of the project.

$2.1[\ldots]$ toate lucrările necesare pentru a asigura conformitatea cu documentele contractului, cele care rezultă din obligațiile contracte precum şi cele care nu sunt enumerate dar care sunt necesare pentru finalizarea integrală şi în sigurantă a proiectului.

(Ctr. No.259/2009 HTC \& Axima: 3)

Another kind of ambiguity may be interpreted in (2), where the term performance - prestare acquires a double meaning. Analysing the sentence in (2), we first understand that the works are performed - prestație, i.e. "the act of doing a piece of work, duty" (Summers). However, the occurrence of the noun phrases a specific date and the essence of the contract reinforce the meaning of the noun phrase performance of the services - prestare a serviciilor: that of a contract agreement.

(2) 2.5 [...], the time of delivery of the goods and of performance of the services is of the essence of the Contract.

$2.5[\ldots]$ momentul livrării de bunuri şi de prestare a serviciilor constituie obiectul contractului.

(Ctr. No. 239/2010 HTC \& Arcons Proiect: 4)

\subsection{Structural and socio-linguistic approach}

A type of ambiguous meaning was encountered in nominal expressions such as performance guarantee and performance warranty. Ambiguity in these situations arose not only due to the use of the noun performance, which, according to the examples above, may lead in certain situations to ambiguous interpretations, but also due to the use of the other constituent element of the nominal structure, i.e. warranty and/or guarantee. According to Martin, warranty in contract law means "a term or promise in a contract, breach of which will entitle the innocent party to damages but not to treat the contract as discharged by breach," while warranty in insurance law is explained as "a promise by the insured, breach of which will entitle the insurer to treat the contract as discharged by breach (Martin 2003: 535). The word has the same meaning as condition in the general law of contract" and another meaning is linked to "a manufacturer's written promise as to the extent 
he will repair, replace, or otherwise compensate for defective goods; a guarantee". Guarantee, on the other hand, is defined as "secondary agreement in which a person (the guarantor) is liable for the debt or default of another (the principal debtor), who is the party primarily liable for the debt". However, the Romanian equivalents of the two terms above are rather ambiguous, as both the noun guarantee, defined as s. garanție, asigurare and warranty, s. garanție, condiție asiguratorie (Năstăsescu 2009: 154) reveal almost the same meaning. Consequently, nominal structures such as performance guarantee and performance warranty, although regarding two different situations in English, may produce ambiguous interpretations in Romanian due to an ambiguous rendering of the terms.

Such situations were encountered within out text analysis; even though the English structures performance guarantee and performance warranty might have referred to different circumstances under the contract, both constructions were translated into Romanian as garanție de bună execuție, leading to ambiguity as to whether the performance of the works undertaken by the contractor is related to "a term or promise in a contract, breach of which will entitle the innocent party to damages but not to treat the contract as discharged by breach," or to a "secondary agreement in which a person (the guarantor) is liable for the debt or default of another (the principal debtor), who is the party primarily liable for the debt” (Martin 2003: 535).

\subsection{Socio-linguistic and cultural discussion}

Regarding the use of the term performance, we have also identified a third different situation. Within various bilingual contracts, we have encountered the compound noun performance bond and its Romanian equivalent scrisoare de garanție bancară. Ambiguity seems to occur in this situation as well. In legal English, Martin (Martin 2003: 535) defines performance bond as "a bond giving security for the carrying out of a contract," which actually means garanție de bună execuție in Romanian. Still, Năstăsescu defines the term bond as I. datorie, creanță II. document de ganație III. angajament de plată; thus, a kind of ambiguity may also arise during the translation process (Năstăsescu 2009: 45), of whether the performance bond refers to 1. A deed by which one person (the obligor) commits himself to another (the obligee) giving security for the carrying out of a contract" (Martin 2003: 52), thus a garanție de bună execuție, or 2. to a financial document issued by a financial institution related to "debt securities by a borrower to investors in return for the payment of a subscription price," namely document de plată or scrisoare de garanție bancară. However, such instances of ambiguity occurred less frequently, as the meaning of the two terms, performance bond - scrisoare de garanție bancară were properly understood and used in accordance with the contract law and language specific to each country. 


\section{Conclusions}

The prevailing analysis method that defines each of the previously mentioned procedures reveals that the linguistic and translation units of the source language are compared to those of the target language in order to reach general operative solutions for the translator.

Aiming to localize some instances of ambiguities that are likely to occur due to the special nature of legal translation, we have established that ambiguities may be localized at the lexical and structural levels, and are explained in terms of inadequate use of English as applied to the highly technical field of legal language. However, ambiguity did not arise necessarily due to translators' misunderstandings or misinterpretations, but also due to social, cultural, and political factors to be taken into consideration when drafting or translating contracts.

Consequently, when translating between two legal systems, ambiguities may be avoided by applying the principle of cultural embeddedness. However, the wider the system gap, the higher the degree of translational difficulty.

\section{Bilingual Corpus}

1. Ctr. No. 22/2009 HTC \& Nestor - Legal Assistance Agreement: Nestor NeStor Diculescu and Hochtief Construction AG Essen

2. Ctr. No. 180/2009 HTC \& Flowtex - Works Contract: Hochtief Construction AG Essen Hochtief Construction AG Essen and S.C. FLOWTEX TECHNOLOGY S.A. Mediaş

3. Ctr. No. 236/2010 HTC \& Autohton TM - Works Contract: Hochtief Construction AG Essen S.C. AUTOHTON TIM S.R.L.

4. Ctr. No. 247/2010 HTC \& Somaco - Purchase Contract: Hochtief Construction AG Essen and Somaco Grup Prefabricate

5. Ctr. No 279/2010 HTC \& Richter Intercom - Works Subcontracting: Hochtief Construction AG Essen and Sc. Richter Intercom Srl.

6. Ctr. No. 230/2008 HTC \& Top Proiect - Consulting Services: Hochtief Construction AG Essen and Top Proiect Consulting

\section{References}

Bussmann, Hadumod. 2006. Dictionary of language and linguistics. Taylor and Francis e-Library.

Cao, Deborah. 2007. Translating law. London: Multilingual Matters Ltd. 
Cruse, Aalan. 2006. A glossary of semantics and pragmatics. Edinburgh: Edinburgh University Press.

Hatim, Basil-Mason, Ian. 1990. Discourse and the translator. London: Longman.

Leech, Geoffrey. 1980. Explorations in semantics and pragmatics. Amsterdam: John Benjamins Publishing House.

Lyons, John. 1995. Linguistic semantics: an introduction. Cambridge: Cambridge University Press.

Martin, A. Elizabeth. 2003. A dictionary of law. Oxford: Oxford University Press.

Nida, Eugene. 2001. Language and culture-contexts in translation. Shanghai: Shanghai Foreign Language Education Press.

Nord, Christiane. 1997. Translating as a purposeful activity: functionalist approaches explained. Manchester: St. Jerome.

Năstăsescu, Violeta. 2009. Dicționar Economic. Englez-Român. Român-Englez. Bucharest: Niculescu.

Oțăt, Diana. 2011. Contracts' lexical features - a synchronic approach”. In: Annals of the University of Craiova. Series: Philology. Applied Linguistics VII(2): 204209. Craiova: Universitaria.

Richards, Jack-Schmidt, Richard. 2006. Longman dictionary of applied linguistics and teaching. London: Pearson Education Ltd.

Summers, Della (ed.). 2005. Longman dictionary of contemporary English. London: Pearson Ltd.

Tambunan, Hanan 2009. The analysis of lexical and structural ambiguity in "Your letters" of Jakarta Post. Medan University of Sumatera Utara.

Tiersma, Peter. 2008. The nature of legal language. In: Gibbons, J.-Turell, T. M. (eds), Dimensions of forensic linguistics. Amsterdam and Philadelphia: John Benjamins, pp. 7-27.

Trosborg, Anna. 1991. An analysis of legal speech acts in English contract laws. In: HERMES. Journal of Linguistics 6: 65-90.

1997. Rhetorical strategies in legal language: discourse analysis of statutes and contracts. Tübigen: Gunter Narr.

Ullmann, Stephen. 1977. Semantics: an introduction to the science of meaning. In: Tambunan, H. A. 2009. The analysis of lexical and structural ambiguity in "Your letters" of Jakarta Post. Medan University of Sumatera Utara.

Vîlceanu, Titela. 2004. Culture-bound items and the translator's visibility. In: Annals of the University of Craiova. Series: Philology - English V(II): 294-302. Craiova: Universitaria.

2008. Intercultural communication. Prerequisites for translation effectiveness. In: University of Bucharest Review. Bucharest Working Papers in Linguistics $\mathrm{X}(2): 35-41$.

Yule, George. 2006. The Study of Language. Third Edition. Cambridge: Cambridge University Press. 